Atıf için / For Citation: A. Yücel, O. Atakol, "Nitro grupları içeren klasik patlayıcı maddelerin indirgenme tepkimeleri ile kimyasal bertaraf yöntemlerinin araştırılması", Süleyman Demirel Üniversitesi Fen Edebiyat Fakültesi Fen Dergisi, 15(1), 45-62, 2020.

\title{
Nitro Grupları İçeren Klasik Patlayıcı Maddelerin İndirgeme Tepkimeleri ile Kimyasal Bertaraf Yöntemlerinin Araștırılması
}

\author{
Abdullah YÜCEL*1, Orhan ATAKOL ${ }^{1}$ \\ ${ }^{1}$ Ankara Üniversitesi, Fen Fakültesi, Kimya Bölümü, 06500, Ankara, Türkiye \\ *yazışllan yazar e-posta: ayucel@ science.ankara.edu.tr
}

(Alınış / Received: 28.08.2019, Kabul / Accepted: 02.03.2020, Yayımlanma / Published: 31.05.2020)

Özet: Askeri amaçlı olarak kullanılan mühimmatın çok büyük bir kısmı nitro grubu içeren enerjik maddelerden üretilmektedir. Nitro grubunun 1 1s1, 1ș1k ve mikroorganizmalardan etkilenen bir fonksiyonlu grup olması mühimmatların bir raf ömrü olmasına ve ömrünü tamamlamıș mühimmatın bertaraf edilmesi problemini ortaya çıkarmaktadır. Günümüzde başvurulan bertaraf yöntemleri enerjik maddenin patlatılması veya yakılması esasına dayanır. Bu yöntemler tedbir alınmış ortamlarda gerçekleştirilmekle birlikte iş güvenliği ve çevre kirliliği açısından risk içerirler. Bu çalışma mühimmat içinde kullanılan enerjik maddelerden 2,4,6-trinitrotoluen, 2,4,6trinitrofenol ve 1,3,5-siklotrimetilentrinitramin bileşiklerinin indirgenme tepkimeleri kullanılarak tehlikesiz materyal haline getirilmeleri üzerine planlanmıştır. Belirtilen enerjik maddeler metalik demir, metalik çinko, sodyumditiyonit, Pd-aktif kömür/hidrazin ve sodyum-cıva amalgamı kullanılarak $\mathrm{MeOH}: \mathrm{H}_{2} \mathrm{O}$ içinde indirgenmişlerdir. İndirgenme ürünleri IR spektroskopi yöntemi ile incelendiğinde, indirgenme ürünleri nitro gruplarının hemen hemen tamamen amino gruplarına indirgendiği tespit edilmiştir. Termogravimetri yöntemi ile indirgenme ürünleri incelendiğinde $\mathrm{Fe} / \mathrm{HCl}$ ve sodyum-civa amalgamı ile indirgenmiş enerjik maddelerin patlama tehlikelerinin ortadan kalktığı görülmüştür.

Anahtar kelimeler: Kimyasal bertaraf, Enerjik maddeler, TNT, RDX, Pikrik asit, Patlayıc1 maddeler

\section{Investigation of Chemical Disposal Methods for Classic Explosives Containing Nitro Groups via Reductive Reactions}

\begin{abstract}
The greater part of the ammunition used for military purposes today is produced from energetic substances containing nitro groups. The fact that a nitro group is a functional group that is affected by heat, light, and microorganisms causes the ammunition to have a lifetime, in parallel the problem of disposal of expired ammunition. Disposal methods used today are based on the explosion or combustion of the energetic material. Although these methods are carried out in precautionary environments, they involve risks in terms of occupational safety and environmental pollution. In this work, the energetic substances used in the ammunition 2,4,6-trinitrotoluene, 2,4,6-trinitrophenol and 1,3,5-cyclotrimethylenetrinitramine compounds using the usual reduction reactions are planned to convert to nonhazardous materials. The stated energetic materials were reduced using iron, metallic zinc, sodium dithionite, Pd-activated charcoal/hydrazine and sodium-mercury amalgam in $\mathrm{MeOH}: \mathrm{H}_{2} \mathrm{O}$. The reduction products were characterized by IR spectroscopy and it was found that the nitro groups in the reduction products were reduced almost exclusively to amino groups. When the reduction products were examined by the thermogravimetry method, it was observed that the explosion hazards of energetic substances reduced with $\mathrm{Fe} / \mathrm{HCl}$ and sodium-mercury amalgam were eliminated.
\end{abstract}

Key words: Chemical disposal, Energetic materials, TNT, RDX, Picric acid, Explosives 


\section{Giriș}

Son 20 yılı kapsayan bir literatür araştırması yapıldığında patlayıcı madde yerine enerjik madde ifadesi kullanıldığı göze çarpmaktadır. Bu terimsel farklılığın sebebi patlayıcı madde alanında yapılan araştırmalarda farklı şekillerde yönelimlerin olmasından kaynaklıdır [1-3]. Karabarut ve $\mathrm{Hg}(\mathrm{OCN})_{2}$ dışında bilimsel anlamda ilk patlayıcı madde üretimini 1846 yılında İtalyan Ascanio Sobrero gerçekleştirmiştir. Sobrero'nun ürettiği ilk patlayıcı madde trinitrogliserin'dir (TNG). Ascanio'dan sonra endüstri devrimi boyunca bu alanda pek çok yeni patlayıcı madde keşfedilmiştir, örneğin Trinitrotoluen 1863 yilında alman kimyager Willbrand tarafindan keşfedilmiş ve ilk olarak 1890-91 yılında mühimmatta kullanılmıştır. Varlığı Johann Rudolf Glauber zamanından beri bilinen 2,4,6 trinitrofenol (pikrik asit) 1885 yılında Herman Sprengel tarafindan patlayıcı madde olarak tanımlanmış ve mühimmatta kullanılmaya başlanmıştır. Yine aynı yıllarda ortaya çıkan nitroselüloz pamuk barutu adı altında İsviçreli kimyager C.F. Schönbein tarafından keşfedilmiştir. 1877'de nitroguanidin (NQ) ve tetril, 1894 'te pentaeritroltetranitrat (PETN), 1899 yılında siklotrimetilentrinitamin (RDX) keşfedilmişlerdir $[1,4,5,6]$. Bu maddelerin yaklaşık tamamı 1. Dünya savaşında mühimmat içeriklerinde kullanılmıştır. 1. Dünya savaşı sonrasında enerjik maddeler konusunda benzer çalışmalar devam etmiş, bu malzemelerin patlama mekanizmaları üzerine araştırmalar yoğunlaşmış bunun yanı sıra yeni enerjik madde sentezi üzerine yoğun çalışmalar yapılmıştır. 2. Dünya savaşı boyunca TNT, PETN, NQ gibi enerjik maddeler çok yoğun olarak kullanılmış, 2. Dünya savaşı sırasında siklotetrametilentetranitramin (HMX veya oktogen) keşfedilmiştir. 2. Dünya savaş1 sonrasında enerjik maddeler üzerine gerçekleştirilen araştırmalar yine organik maddelerin nitrolanması yönünde olmuştur. Bunun sonucu olarak nitro grubu yoğunluğunun fazla olduğu enerjik maddeler ortaya çıkmıştır. Hekzanitrostilben (HNS), 1966 yılında, 1978 yılında hekzanitrohekzaazawürtzitat (CL-20), 1987 yılında oktanitroküban (ONC) gibi karbon başına nitro grubunun yoğun olduğu enerjik maddeler keşfedilmiştir [1]. 1980 'li yılların başından itibaren enerjik madde araştırmaları farklı yönlere kaymış ve çoğunlukla azotça zengin moleküllerin sentezi üzerinde yoğunlaşmıştır, nitro-1,2,4-triazol-5-on (NTO), trinitrotriaminobenzen (TATB), N(pikril)-3-amino-1,2,4-triazol (PATO) gibi patlayıcılar bu düşünce ile hazırlanmışlardır [1,5]. Nitro gruplarından kaçınılmasının nedeni nitro gruplarının aşırı elektron çekici etkileri sebebiyle molekülleri dengesizleştirmesi ve 1sı, 1şık veya mikrobiyal olarak malzemenin bozunmasına sebep olmasıdır. Bunun yanı sıra dengesiz moleküllerin termal ve darbe hassaslıkları oldukça düşük olduğundan nitro grubu taşıyan enerjik maddelerin güven seviyesi düşük ve can güvenliği riski oldukça yüksektir.

Günümüzdeki enerjik madde araştırmalarında güvenlik ve dayanıklılık birincil hedef olarak görülmektedir $[1,7,8]$. Ancak günümüzde kullanılan mühimmatların içindeki enerjik maddeler hala nitrolu klasik malzemelerdir ve bu malzemelerin belli bir raf ömürleri vardır. Raf ömürleri mühimmat içindeki nitro gruplarının bozunması ve mühimmatın özelliğini kaybetmesi üzerine belirlenmiş değerlerdir. Nitro grubu içeren organik moleküller 1 şı altında oldukça hızlı bir şekilde bozunma tepkimelerine girebilmektedirler. Toprak ile temasta olan nitrolu enerjik maddelerde mikroorganizmalar enerjik maddeleri indirgenme ürünlerine dönüştürebilmektedirler [9]. Bu sebeplerden dolayı raf ömrünü tamamlamış olan mühimmatın bertaraf edilmesi gerekmektedir. $\mathrm{Bu}$ bertaraf dünya genelinde mühimmatın tehlikesiz bir arazide patlatılması veya yakılması şeklinde gerçekleştirilmektedir. Mühimmatın içindeki enerjik maddelerin geri kazanımı üzerine çok sınırlı sayıda çalışma olduğu gibi bu enerjik malzemelerin mikroorganizmalar yoluyla parçalanması ve bertaraf edilmesi üzerine ve kimyasal tepkimelelerle etkisizleştirilmesi üzerine çalışmalarda çok sınırlıdır. Bunun sebebi büyük olasılıkla 
enerjik maddelerin potansiyel patlama tehlikesi olmasından dolayı kimyacıların ve biyoteknoloji çalışanlarının bu maddelerle çalışmaktan kaçınmasıdır. Ancak 1980'li yılların başından itibaren ortaya çıkan azotça zengin enerjik madde sentezinin temel amaçlarından bir tanesi daha yeşil malzemeler elde etmek, daha çevre dostu enerjik madde üretimidir, mühimmat içindeki enerjik maddelerin yakılması veya patlatılması çevre dostu bir uygulama değildir [10].

$\mathrm{Bu}$ çalışma bu bağlamda mühimmatlarda kullanılan enerjik maddelerin kimyasal yöntemle bertaraf edilip edilemeyecekleri üzerine planlanmış bir çalışmadır. Nitrobenzenlerin indirgen metaller yanında anilinlere indirgenmesi çok uzun zamandan beri bilindiğinden çeşitli indirgenler kullanılarak enerjik maddelerdeki nitro gruplarının indirgenmesi sonucu enerjik maddenin patlayıcı özelliğinin kaybolup kaybolmadığının araştırılması yapılmıştır [11-12]. Bu konuda literatürde çalışma çok azdır. 1990-2000 arasında yayınlanmış iki çalışma literatürde görülmüştür $[13,14]$. Literatürdeki bu çalışmalarda TNT, RDX ve HMX maddelerinin otoklavda yüksek sicaklıkta bazik ortamda parçalanmaları incelenmiş ve kimyasal yolla enerjik maddelerin tehlikesizce parçalanabildikleri rapor edilmiştir.

Sunulan bu çalışmada da laboratuarımızda hazırlanmış olan ve IR spektroskopi, MS, ${ }^{1} \mathrm{HNMR}$ ve ${ }^{13} \mathrm{CNMR}$ yöntemleriyle karakterize edilmiş olan TNT, RDX ve Pikrik asidin metalik $\mathrm{Fe}$, metalik $\mathrm{Zn}$, aktif kömür üzerine dop edilmiş $\mathrm{Pd}, \mathrm{Na}_{2} \mathrm{~S}_{2} \mathrm{O}_{4}, \% 3$ lük $\mathrm{NaHg}$ kullanılarak nitro gruplarının indirgenip indirgenmedikleri araştırılmış ve enerjik maddenin patlayıcı özelliğinin ortadan kalkıp kalkmadığı termal analiz yöntemlerinden termogravimetri yöntemi kullanılarak araştırılmıştır. İndirgemeler uygulamaya yönelik olması amacıyla sulu ortamda gerçekleştirilmiş fakat çözünürlüğü sağlamak üzere $\mathrm{MeOH}: \mathrm{H}_{2} \mathrm{O}$ karışımları tercih edilmiştir [15].

\section{Materyal ve Metot}

Hazırlanan enerjik maddelerin ve indirgeme ürünlerinin karakterizasyonu Shimadzu marka Infinity model, 3 yansimalı ATR ekipmanı bulunan Fourier transform IR spektrometresi ile yapılmıştır. Cihazın dedektörü DLTGS (Dötörolanmıl lantan triglisinsülfat) tipi piroelektrik kristal dedektör olup ayırma gücü (rezolüsyon) $4 \mathrm{~cm}^{-1}$ değerinde çalışılmıştır. ${ }^{1} \mathrm{HNMR}$ ve ${ }^{13} \mathrm{CNMR}$ spektrumları Bruker Ultrashield $300 \mathrm{MHz}$ NMR ve spektrumlar d6-DMSO çözücüsü içinde kaydedilmiştir. Termogravimetrik incelemeler ise Shimadzu DTG $60 \mathrm{H}$ cihazında Pt pan kullanılarak çoğunlukla 10 ${ }^{\circ} \mathrm{C} /$ dakika 1 sıtma hızlarında $\mathrm{N}_{2}$ atmosferinde yapılmıştır. Ayrıca $5{ }^{\circ} \mathrm{C} /$ dakika veya daha düşük ısıtma hızlarında da çalışılmıştır. Hem enerjik maddelerin hem de indirgenme ürünlerinin kütle spektrumları Shimadzu 2010 Plus GCMS cihazında kaydedilmiştir. Ancak çalışılan maddeler GC kolonu içinden geçirilmeden direkt Inlet (DI) ekipmanı yardımıyla elektron iyonlaştırma $70 \mathrm{eV}$ enerjili elektronlarla yöntemiyle iyonlaştırılarak ve $\mathrm{m} / \mathrm{z}$ değerleri belirlenmiştir.

\subsection{Enerjik maddeler ve deneysel çalışmalarda kullanılan kimyasalların hazırlanması}

\subsubsection{2,4,6-Trinitrofenol hazırlanmast}

9.4 g Fenol ve $40 \mathrm{ml} \% 63$ 'lük $\mathrm{HNO}_{3}$ 'ten ilgili literatüre göre hazırlanmıştır [15]. $50 \mathrm{ml}$ derişik $\mathrm{H}_{2} \mathrm{SO}_{4} 500$ mL'lik bir yuvarlak dipli çift boyunlu balonda tuz-buz banyosunda sıcaklığı yaklaşık $0{ }^{\circ} \mathrm{C}$ olana kadar soğutularak, üzerine $9,4 \mathrm{~g}$ fenol katı olarak eklenmiş ve bir magnetik karıştırıcıda karıştırılarak sıcaklık $25-30^{\circ} \mathrm{C}$ olana kadar 1sıtılmıştır. Daha sonra bu karışıma $20 \mathrm{~mL} \% 63$ 'lük $\mathrm{HNO}_{3}$ yavaş yavaş eklenerek sıcaklık $60^{\circ} \mathrm{C}$ olana kadar 
karıştırılarak çeker ocak içerisinde 1 sıtılmıştır. Karışım yaklaşık 1 saat $60^{\circ} \mathrm{C}$ sıcaklıkta bekletildikten sonra sicaklık $100^{\circ} \mathrm{C}$ 'a olana kadar isıtılmış ve $20 \mathrm{~mL} \% 63$ 'lük $\mathrm{HNO}_{3}$ bir damlatma hunisi yardımıyla yavaş yavaş eklenmiştir. \%63'lük $\mathrm{HNO}_{3}$ ilavesi sonrasında 1 saat magnetik karıştırıcıda karıştırılan karışım buz-su karışımına dökülmüş ve ayrılan katı madde Nutsche hunisi yardımıyla süzülerek, EtOH: $\mathrm{H}_{2} \mathrm{O}(2: 3, \mathrm{v} / \mathrm{v})$ karışımında rekristalize edilmiş ve sıcaklığ $160^{\circ} \mathrm{C}$ olan bir etüvde kurutulmuştur [15].

Tablo 1. 2,4,6-Trinitrofenol karakterizasyon verileri

\begin{tabular}{|c|c|}
\hline \multicolumn{2}{|c|}{$\mathrm{C}_{6} \mathrm{H}_{2}\left(\mathrm{NO}_{2}\right)_{3} \mathrm{OH}$} \\
\hline Erime noktas1 & $121,8^{\circ} \mathrm{C}$ \\
\hline Verim & $\% 78$. \\
\hline Önemli IR dataları (cm-1) & $\begin{array}{c}\nu \mathrm{C}-\mathrm{H}(\mathrm{Ar}): 3091-3057, v \mathrm{C}-\mathrm{H}(\text { Aliph }): 2954- \\
2887, v \mathrm{C}=\mathrm{N}(\text { rezonance }): 1604-1620 \\
v \mathrm{C}=\mathrm{C}(\text { ring }): 1531, \delta \mathrm{CH}_{3}: 1404 \\
v \mathrm{~N}=\mathrm{O}: 1306, \delta \mathrm{C}-\mathrm{H}(\mathrm{Ar}): 702\end{array}$ \\
\hline${ }^{1} \mathrm{HNMR}$ dataları, $\delta$, d6-DMSO içinde & $9,04,2,46$ \\
\hline${ }^{13} \mathrm{CNMR}$ dataları, $\delta$, d6-DMSO içinde & $\begin{array}{c}\text { d6-DMSO içinde: } 154,55,139,82 \\
\text { 135,23, } 126,04, \\
\text { m/z: } 229 \text { (moleküler pik ve temel pik), } \\
199,91,69,62,30\end{array}$ \\
\hline
\end{tabular}

\subsubsection{Siklotrimetilentrinitramin (RDX, hekzogen, hekzahidro-1,3,5-trinitro-1,3,5- triazin) hazırlanmast}

$110 \mathrm{~mL} \% 99,5^{\prime}$ luk $\mathrm{HNO}_{3}$ ve $10 \mathrm{~g}$ hekzametilen tetramin kullanılarak ilgili literatüre göre hazırlandı [16]. İki ağızlı bir balon içerisinde $110 \mathrm{~mL} \% 99,5$ 'luk HNO3 tuz-buz banyosunda yaklaşık $0^{\circ} \mathrm{C}$ sicaklığa kadar soğutulmuş ve balona $10 \mathrm{~g}$ hekzametilen tetramin yavaş yavaş eklenmiştir. $\mathrm{Bu}$ işlem sırasında sıcaklığın $10^{\circ} \mathrm{C}^{\prime} 1$ geçmemesine dikkat edilerek çözelti magnetik karıştırıcıda 1 saat karıştırılmıştır. Daha sonra çözelti $75^{\circ} \mathrm{C}$ sıcaklığa ulaşana kadar 1sıtılmış ve $75^{\circ} \mathrm{C}$ ' de $10 \mathrm{~mL} \% 63$ 'lük $\mathrm{HNO}_{3}$ ve $2 \mathrm{~g} \mathrm{NaNO}_{2}$ eklenmiştir. Bu sıcaklıkta 1 saat karıştırılan çözelti buz-su karışımına dökülmüş ve çöken sarı-beyaz renkli madde süzülerek ayrılmış ve etüvde $55^{\circ} \mathrm{C}$ sıcaklıkta kurutulmuştur [16].

Tablo 2. Siklotrimetilentrinitramin karakterizasyon verileri

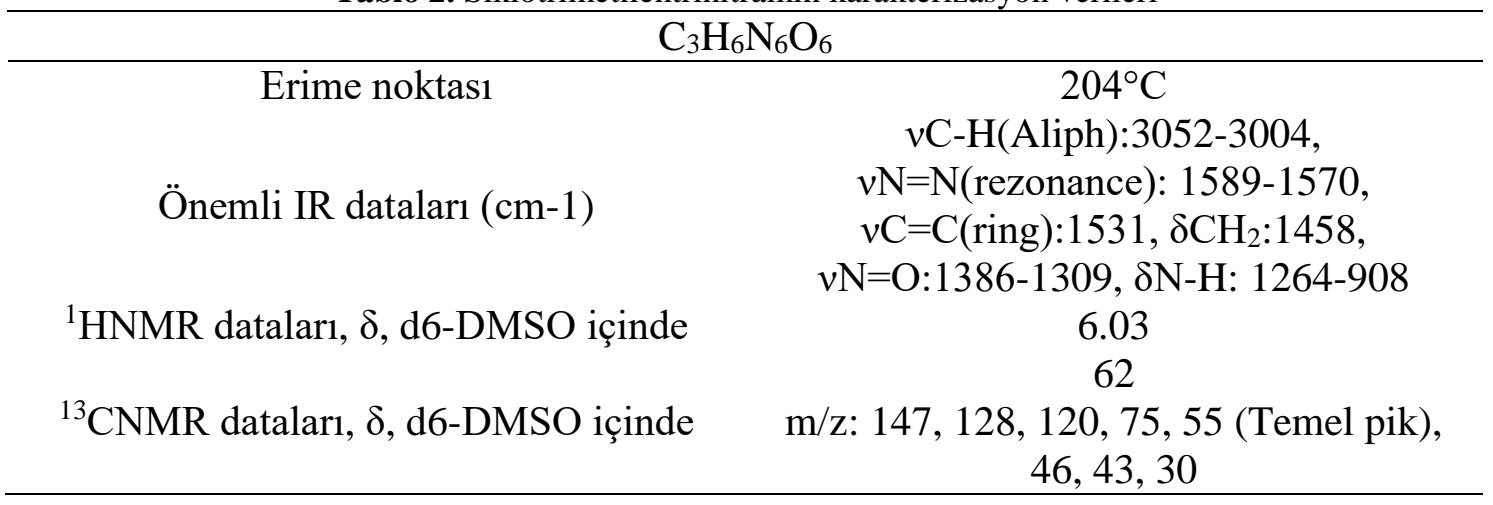

\subsubsection{2,4,6-Trinitrotoluen (TNT) Hazırlanması}

9,2 g Toluen, $100 \mathrm{~mL} \% 98$ 'lik $\mathrm{H}_{2} \mathrm{SO}_{4}$ ve $50 \mathrm{~mL} \% 99$,5'luk $\mathrm{HNO}_{3}$ ’ten ilgili literatüre göre hazırlandı [17]. $100 \mathrm{~mL} \% 98$ 'lik $\mathrm{H}_{2} \mathrm{SO}_{4}$ iki ağızlı bir balonda tuz-buz banyosu yardımıyla yaklaşık $0{ }^{\circ} \mathrm{C}$ sicaklığa ulaşana kadar soğutulmuş ve üzerine $9.2 \mathrm{~g}$ toluen yavaş yavaş karıştırılarak eklenmiştir. $\mathrm{Bu}$ karışıma $50 \mathrm{ml} \% 99,5^{\prime}$ luk $\mathrm{HNO}_{3}$ yavaş yavaş eklenerek sıcaklık kontrollü olarak $100^{\circ} \mathrm{C}$ 'a yükseltilmiştir. Karışım aynı sıcaklıkta yaklaşık 2 saat 
karıştırıldıktan sonra sıcaklık $120^{\circ} \mathrm{C}$ 'a çıkarılarak yarım saat bu sıcaklıkta karıştırmaya devam edilmiştir. Bu süre sonunda 1sıtmaya son verilerek karışım soğutulmuş ve daha sonra buz-su karışımına dökülmüştür. Elde edilen sarı renkli çökelek süzülerek ayrılmış ve hava ortamında kurutulmuştur. Son olarak EtOH: $\mathrm{H}_{2} \mathrm{O}$ kullanılarak rekristalize edilmiştir [17].

Tablo 3. 2,4,6-Trinitrotoluen karakterizasyon verileri

\begin{tabular}{cc}
\hline & $\mathrm{C}_{7} \mathrm{H}_{5} \mathrm{~N}_{3} \mathrm{O}_{6}$ \\
\hline Erime noktas1 & $81,4^{\circ} \mathrm{C}$ \\
Verim & $\% 75$ \\
& $v \mathrm{C}-\mathrm{H}(\mathrm{Ar}): 3094-3047, v \mathrm{C}=\mathrm{C}(\mathrm{ring}): 1531$, \\
& $\delta \mathrm{CH} 2: 1458, \delta \mathrm{CH}_{3}: 1404, v \mathrm{~N}=\mathrm{O}: 1305$, \\
& $\delta \mathrm{C}-\mathrm{H}(\mathrm{Ar}): 715$ \\
Önemli IR dataları $(\mathrm{cm}-1)$ & $8,83,2,62$ \\
& $152,28,146,71,134,91,122,16,18,01$ \\
& $\mathrm{~m} / \mathrm{z}: 210,193,180,163,120,89,77,46$, \\
& 30 \\
${ }^{1} \mathrm{HNMR}$ dataları, $\delta$, d6-DMSO içinde & \\
& \\
&
\end{tabular}

\subsubsection{NaHg Amalgam hazırlanması}

Sodyum amalgamı yaklaşık \%2,5 - 3,0 olacak şekilde literatürde verilen yöntemin modifiye haliyle hazırlandı [18]. Literatürde bu maddenin toluen içinde hazırlandığı belirtilmiş ancak çalışmada ekzotermik çözünme nedeni ile toluen kullanılmadan amalgam hazırlanmıştır. Büyük bir havan içinde yaklaşık $300 \mathrm{~g}$ yeni temizlenmiş cıva konularak oda sıcaklığında bu cıva üzerine 0,5-1,0 g'lık küçük parçalar halinde yeni kesilmiş $\mathrm{Na}$ eklenmiş ve $\mathrm{Na}$ metalleri havan tokmağı ile bastırılarak $\mathrm{Na}$ 'nın $\mathrm{Hg}$ içinde çözülmesi sağlanmıştır. Yaklaşık $10 \mathrm{~g}$ Na metali çözüldükten sonra havan bir çeker ocak içinde kendi haline bırakılmış ve oda sıcaklığına kadar soğuması sağlanmıştır. Havan ters döndürülerek bir kalıp halinde katı amalgam çıkarılmıştır. Yaklaşık 5-10 g'lık parçalar halinde bir çekiç yardımıyla parçalanmış ve kapalı bir şişe içinde desikatörde saklanmıştır.

$\mathrm{Na}$ metalinin $\mathrm{Hg}$ içinde çözülmesi kuvvetli ekzotermik bir tepkime olduğundan ilk Na parçalarının eklenmesi esnasında havan içinden kıvılcım veya alev çıkabilir ve havan şiddetle 1sınır. Bu sebeple yanıcı kimyasalların alandan uzaklaştırılması, tam yüz koruyucu maske ve koruma gözlüğü kullanılması zorunludur.

\section{2 İndirgeme tepkimelerinin gerçekleştirilmesi}

\subsubsection{Metalik indirgenlerle yapulan indirgeme tepkimeleri}

Yuvarlak dipli bir iki ağızlı balonda yaklaşık $1.0 \mathrm{~g}$ Pikrik asit, RDX veya TNT alınarak $50 \mathrm{ml} \mathrm{MeOH}: \mathrm{H}_{2} \mathrm{O}(3: 1$, v/v) karışımında hafifçe 1sıtılarak çözülmüştür. Hazırlanan çözeltiye farklı deneylerde $1.0 \mathrm{~g}$ Fe ve $1.0 \mathrm{~g}$ Zn tozu katılmış, ardından $10 \mathrm{ml} \% 30$-33'lük $10 \mathrm{~mL} \mathrm{HCl}$ damla damla eklenerek 4 saat boyunca sıcaklık yaklaşı $50{ }^{\circ} \mathrm{C}$ civarında tutularak karıştırılmıştır. Bu süre sonunda her deneye yarım saat aralıklar ile üç kez $0,5 \mathrm{~g}$ içeriğindeki metal tozu (0,5 g Fe veya $0,5 \mathrm{~g}$ Zn tozu) ve $4-5 \mathrm{~mL} \% 30-33$ 'lük HCl eklemesi yapılarak 2 saat daha tepkime sürdürülmüştür. Bu süre sonunda karışım bir Nutsche hunisinden süzülmüş ve elde edilen bordo-kahverengi çözelti yavaş yavaş bir 1sitıcı üzerinde kuruluğa kadar buharlaştırılmıştır. İşlem sonunda ele geçen madde beherden kazınarak alınmıştır [19-20]. 


\subsection{2 $\mathrm{Na}_{2} \mathrm{~S}_{2} \mathrm{O}_{4}$ ile yapulan indirgeme Tepkimeleri}

Yuvarlak dipli bir iki ağızlı balonda yaklaşık $1.0 \mathrm{~g}$ Pikrik asit, RDX veya TNT alınarak $50 \mathrm{ml} \mathrm{MeOH}: \mathrm{H}_{2} \mathrm{O}(3: 1$, v/v) karışımında hafifçe 1sıtılarak çözülmüştür. Karıştırılan çözeltiye $2.0 \mathrm{~g} \mathrm{Na}_{2} \mathrm{~S}_{2} \mathrm{O}_{4}$ katılmış, ardından $10 \mathrm{ml} \% 30$-33'lük $\mathrm{HCl}$ damla damla eklenerek 4 saat boyunca sicaklık $70{ }^{\circ} \mathrm{C}$ civarında tutularak karıştırılmıştır. Bu süre sonunda yaklaşık yarım saat aralıklarla $4 \mathrm{kez} 0,75 \mathrm{~g} \mathrm{Na}_{2} \mathrm{~S}_{2} \mathrm{O}_{4}$ ve 4-5 mL \%30-33'lük $\mathrm{HCl}$ eklemesi yapılarak tepkime sürdürülmüştür. Akabinde karışım bir Nutsche hunisinden süzülmüş ve elde edilen çözelti yavaş yavaş bir 1sıtıcı üzerinde kuruluğa kadar buharlaştırılmıştır. İşlem sonunda ele geçen madde beherden kazınarak alınmıştır [21-22].

\subsubsection{Na-Hg Amalgamı ile yapılan indirgeme Tepkimeleri}

Yuvarlak dipli bir iki ağızlı balonda yaklaşık $1.0 \mathrm{~g}$ Pikrik asit, RDX veya TNT alınarak $50 \mathrm{ml} \mathrm{MeOH}: \mathrm{H}_{2} \mathrm{O}(3: 1$, v/v) karışımında hafifçe isıtılarak çözülmüştür. Karıştırılan çözeltiye 10.0 g Na-Hg (\%2,5-3,0) katılarak çözelti bir mekanik karıştırıcı ile karıştırılmıştır. Çözelti sürekli bazik hale geldiğinden 15-20 dakikalık zaman aralıklarıyla 2,0 mL \%30-33'lük HCl damla damla eklenerek çözeltinin nötral kalması pH kağıdı ile kontrol edilerek sağlanmıştır. 4 saat boyunca karıştırılan çözeltiye bu süre sonunda yarım saat aralıklarla $3 \mathrm{kez}$ 10,0 g Na-Hg amalgamı, 2,0 mL \%30-33 lük $\mathrm{HCl}$ eklemesi gerçekleştirilmiş ve 2 saat daha çözelti karıştırılmıştır. Bu süre sonunda balonun dibinde biriken sıvı haldeki amalgam bir ayırma hunisi yardımıyla ayrılmış ve bolca $\mathrm{HCl}$ yardımıyla metalik $\mathrm{Hg}^{6}$ ye dönüşmesi sağlanmıştır. Ayrılan çözelti bir Nutsche hunisinden süzülmüş ve elde edilen çözelti yavaş yavaş bir 1sıtıcı üzerinde kuruluğa kadar buharlaştırılmıştır. İşlem sonunda ele geçen madde beherden kazınarak alınmıştır [1920].

\subsubsection{Aktif $\mathrm{C} / \mathrm{Pd}-\mathrm{N}_{2} \mathrm{H}_{4}$ ile yapılan indirgeme tepkimeleri}

Yuvarlak dipli bir iki ağızlı balonda yaklaşık $1.0 \mathrm{~g}$ Pikrik asit, RDX veya TNT alınarak $50 \mathrm{ml} \mathrm{MeOH}: \mathrm{H}_{2} \mathrm{O}(3: 1$, v/v) karışımında 1sıtılarak çözülmüştür. Kaynama sıcaklığına kadar 1sitılan çözelti üzerine $0,2 \mathrm{~g}$ civarında $\mathrm{Pd}$ aktif $\mathrm{C}$ ve $10 \mathrm{~mL}$ hidrazin damla damla ilave edilmiştir. Karışım kaynama noktasında 4 saat karıştırılmıştır. Ardınan 4'er saatlik üç tekrarla 5'er mL hidrazin ilavesi ile ısıtarak karıştırma işlemine devam edilmiştir. Reaksiyon sonunda çözelti buchner hunisinden süzülmüş ve çözelti çeker ocakta buharlaştırılarak çökelek ürün alınmıştır. Süzülen aktif C/Pd 3-4 kez EtOH ve $\mathrm{H}_{2} \mathrm{O}$ ile yıkandıktan sonra $200^{\circ} \mathrm{C}$ sıcaklıktaki bir etüv içinde 3 saat bekletilerek yeniden aktivasyonu sağlanmıştır ve kullanılmak üzere ayrılmıştır [19-20].

\section{Bulgular}

İndirgenme ürünlerinin her bir enerjik madde için kaydedilen IR spektrumları Şekil 1, Şekil 2, Şekil 3, Şekil 4, Şekil 5, Şekil 6 da paylaşılmıştır. IR spektrumlarında parmak izi bölgesi çok karmaşık olduğundan indirgenme ürünlerinin IR spektrumları iki grup halinde verilmiştir. Üç enerjik maddeden, Pikrik asidin, iki metalik indirgen, Fe ve Zn ile yapılan indirgenme tepkimesi sonucu elde edilen ürünlerin IR spektrumları Şekil 1 de, diğer indirgenle elde edilen ürünlerin IR spektrumları Şekil 2 de, RDX'in indirgenme ürünlerinin IR spektrumları Şekil 3 ve Şekil 4 de, TNT'nin indirgenme ürünlerinin IR spektrumları Şekil 5 ve Şekil 6 da sırasıyla verilmiştir. 


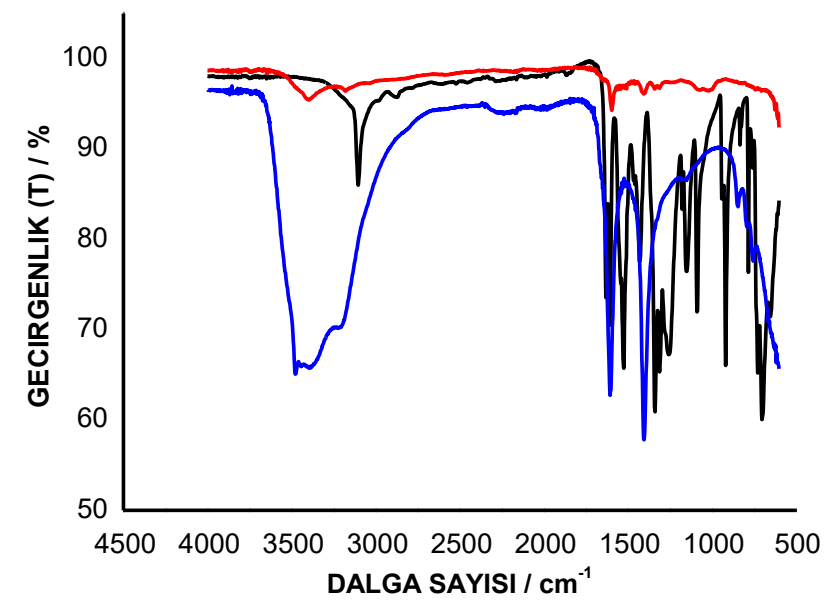

Şekil 1. Pikrik asidin metalik Fe ve metalik $\mathrm{Zn}$ ile asitli ortamda indirgenme ürünlerinin kaydedilen IR spektrumları, siyah: Pikrik asit, kırmızı: $\mathrm{Fe} / \mathrm{HCl}$ indirgenme ürünü, mavi: $\mathrm{Zn} / \mathrm{HCl}$ indirgenme ürünü

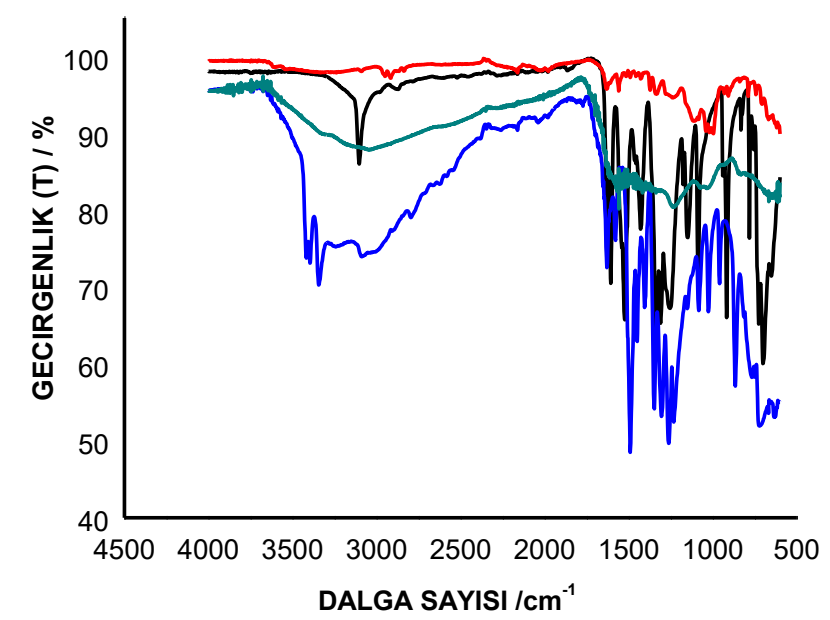

Şekil 2. Pikrik asidin $\mathrm{Na}_{2} \mathrm{~S}_{2} \mathrm{O}_{4}, \mathrm{Na}-\mathrm{Hg}$ amalgamı ve aktif $\mathrm{C} / \mathrm{Pd}-\mathrm{N}_{2} \mathrm{H}_{4}$ ile indirgenme ürünlerinin IR spektrumları, siyah: pikrik asit, kırmızı: $\mathrm{Na}_{2} \mathrm{~S}_{2} \mathrm{O}_{4}$ ile indirgenme ürünü, mavi: $\mathrm{Na}-\mathrm{Hg}$ amalgamı ile indirgenme ürünü, koyu yeşil: aktif $\mathrm{C} / \mathrm{Pd}-\mathrm{N}_{2} \mathrm{H}_{4}$ indirgenme ürünü

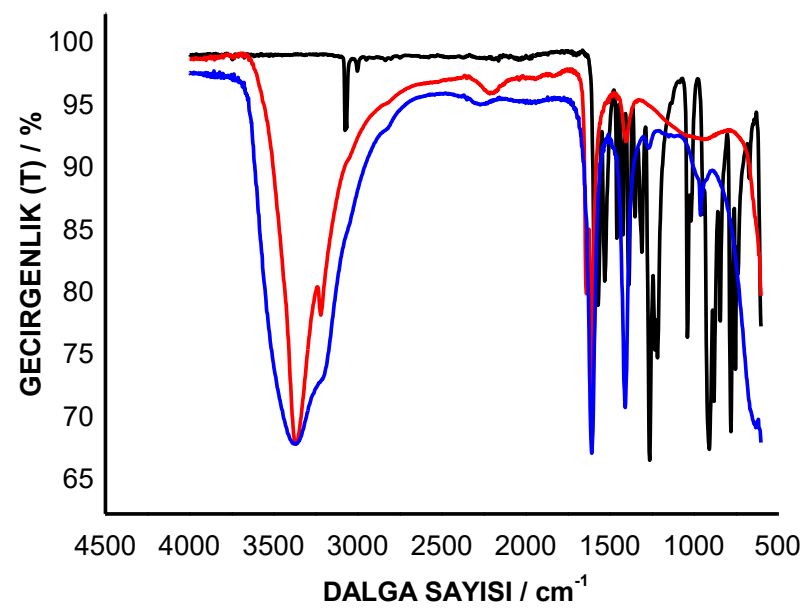

Şekil 3. RDX'in metalik Fe ve metalik $\mathrm{Zn}$ ile asitli ortamda indirgenme ürünlerinin kaydedilen IR spektrumları, siyah: Pikrik asit, kırmızı: $\mathrm{Fe} / \mathrm{HCl}$ indirgenme ürünü, mavi: $\mathrm{Zn} / \mathrm{HCl}$ indirgenme ürünü 


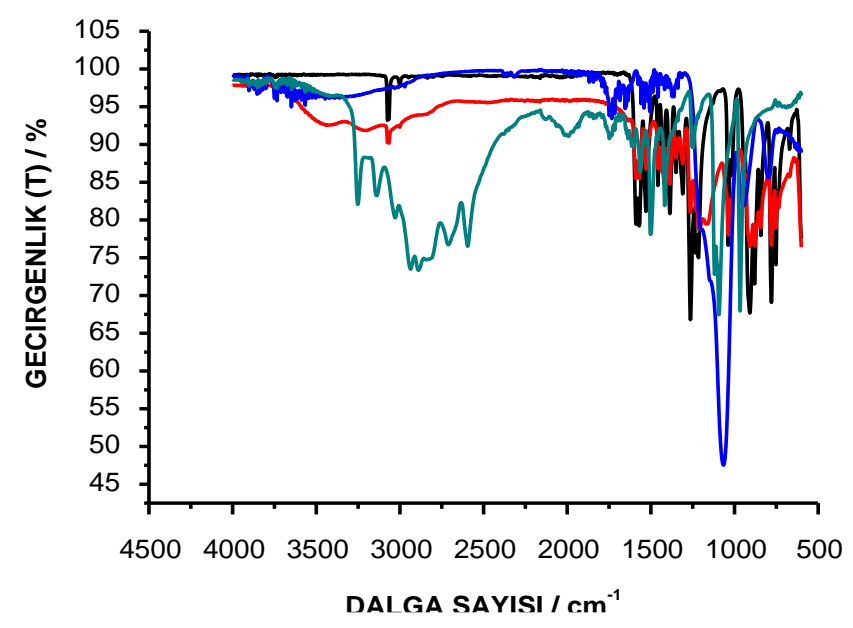

Şekil 4. $\mathrm{RDX}$ ' in $\mathrm{Na}_{2} \mathrm{~S}_{2} \mathrm{O}_{4}, \mathrm{Na}-\mathrm{Hg}$ amalgamı ve aktif C/Pd- $\mathrm{N}_{2} \mathrm{H}_{4}$ ile indirgenme ürünlerinin IR spektrumları, siyah: pikrik asit, kırmız1: $\mathrm{Na}_{2} \mathrm{~S}_{2} \mathrm{O}_{4}$ ile indirgenme ürünü, mavi: $\mathrm{Na}-\mathrm{Hg}$ amalgamı ile indirgenme ürünü, koyu yeşil: aktif C/Pd- $\mathrm{N}_{2} \mathrm{H}_{4}$ indirgenme ürünü

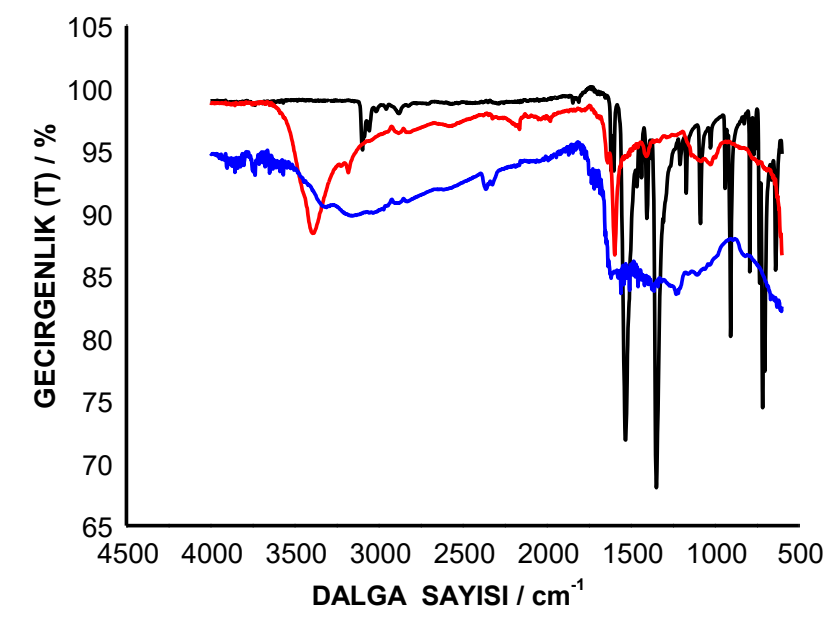

Şekil 5. TNT'nin metalik Fe ve metalik Zn ile asitli ortamda indirgenme ürünlerinin kaydedilen IR spektrumları, siyah: Pikrik asit, kırmızı: $\mathrm{Fe} / \mathrm{HCl}$ indirgenme ürünü, mavi: $\mathrm{Zn} / \mathrm{HCl}$ indirgenme ürünü

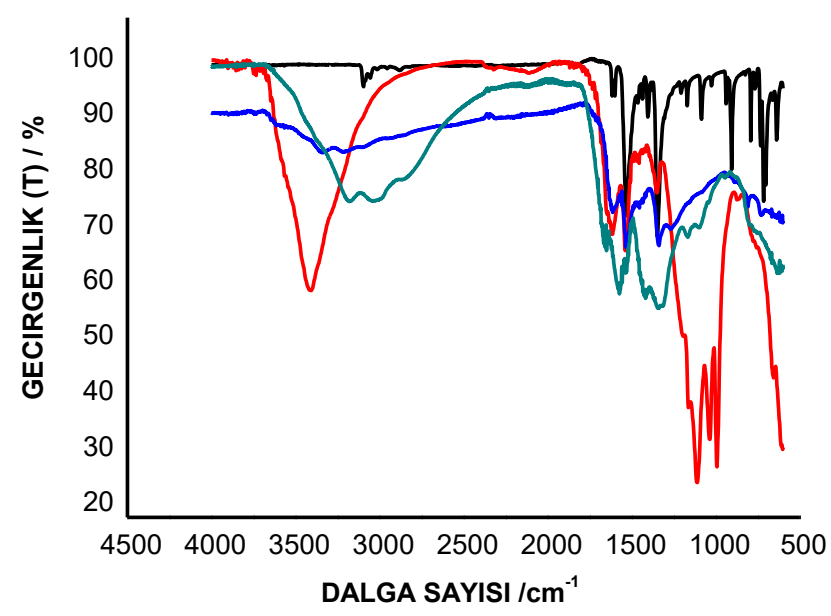

Şekil 6. TNT'nin $\mathrm{Na}_{2} \mathrm{~S}_{2} \mathrm{O}_{4}, \mathrm{Na}-\mathrm{Hg}$ amalgamı ve aktif $\mathrm{C} / \mathrm{Pd}-\mathrm{N}_{2} \mathrm{H}_{4}$ ile indirgenme ürünlerinin IR spektrumları, siyah: pikrik asit, kırmızı: $\mathrm{Na}_{2} \mathrm{~S}_{2} \mathrm{O}_{4}$ ile indirgenme ürünü, mavi: Na-Hg amalgamı ile indirgenme ürünü, koyu yeşil: aktif $\mathrm{C} / \mathrm{Pd}-\mathrm{N}_{2} \mathrm{H}_{4}$ indirgenme ürünü 
Kullanılan enerjik maddelerin Pikrik asit, RDX, TNT'nin ve indirgenme ürünlerinin TG - DTA incelemesi sonucunda elde edilen TG eğrileri karşılaştırmalı olarak Şekil 7, Şekil 8 ve Şekil 9'da, DTA eğrileri ise Şekil 10, Şekil 11, Şekil 12'de sırasıyla verilmiştir. TG sonuçlarından elde edilmiş olan termoanalitik veri ise Tablo 4 de görülmektedir.

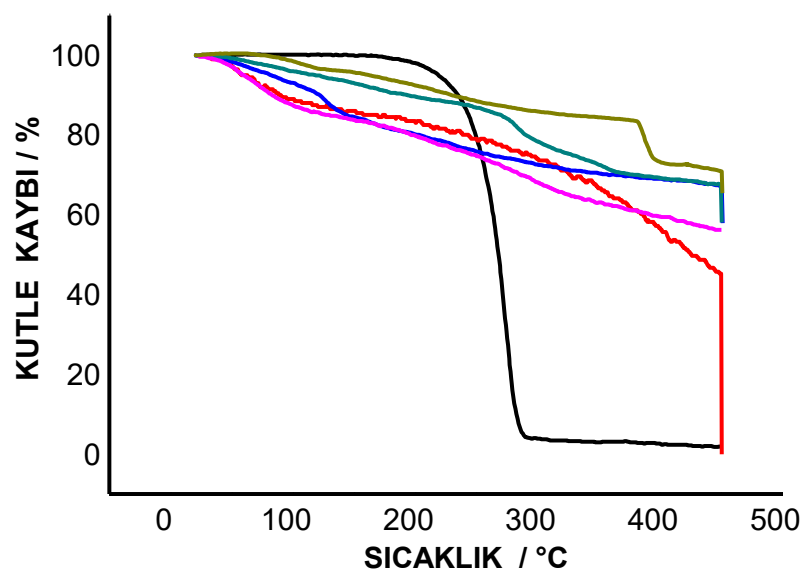

Şekil 7. Pikrik asidin kullanılan indirgenler ile indirgenmesinden elde edilen ürünlerin TG eğrileri, siyah: pikrik asit, kırmızı: $\mathrm{Fe} / \mathrm{HCl}$ ile indirgenme ürünü, mavi: $\mathrm{Na}_{2} \mathrm{~S}_{2} \mathrm{O}_{4}$ ile indirgenme ürünü, koyu yeşil: $\mathrm{Na}-\mathrm{Hg}$ amalgamı ile indirgenme ürünü, pembe: aktif $\mathrm{C} / \mathrm{Pd}-\mathrm{N}_{2} \mathrm{H}_{4}$ ile indirgenme ürünü, açık yeşil: $\mathrm{Zn} / \mathrm{HCl}$ ile indirgenme ürünü

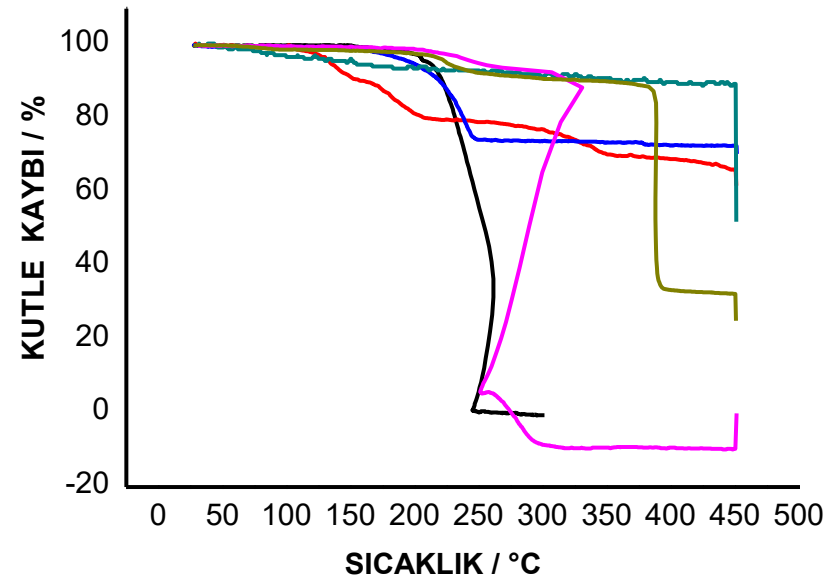

Şekil 8. RDX'in kullanılan indirgenler ile indirgenmesinden elde edilen ürünlerin TG eğrileri, siyah: RDX, kırmızı: $\mathrm{Fe} / \mathrm{HCl}$ ile indirgenme ürünü, mavi: $\mathrm{Na}_{2} \mathrm{~S}_{2} \mathrm{O}_{4}$ ile indirgenme ürünü, koyu yeşil: $\mathrm{Na}-\mathrm{Hg}$ amalgamı ile indirgenme ürünü, pembe: aktif $\mathrm{C} / \mathrm{Pd}-\mathrm{N}_{2} \mathrm{H}_{4}$ ile indirgenme ürünü, açık yeşil: $\mathrm{Zn} / \mathrm{HCl}$ ile indirgenme ürünü 


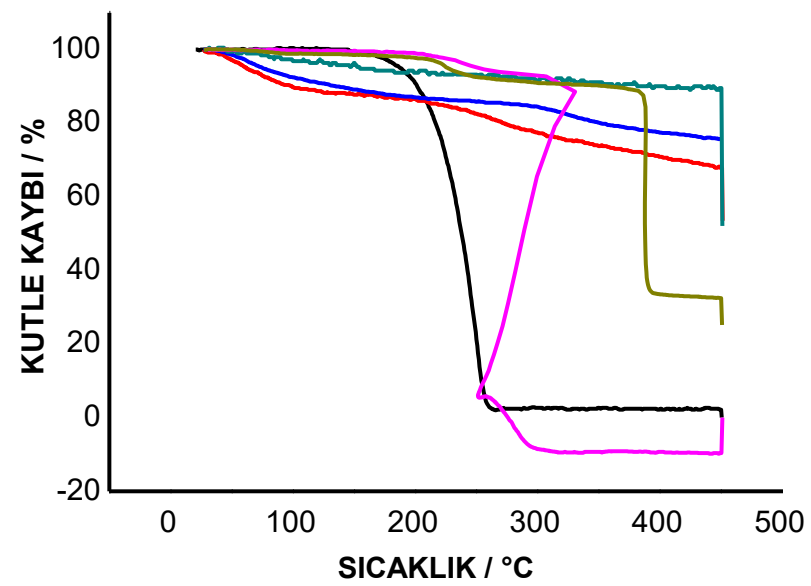

Şekil 9. TNT'nin kullanılan indirgenler ile indirgenmesinden elde edilen ürünlerin TG eğrileri, siyah: TNT, kırmızı: $\mathrm{Fe} / \mathrm{HCl}$ ile indirgenme ürünü, mavi: $\mathrm{Na}_{2} \mathrm{~S}_{2} \mathrm{O}_{4}$ ile indirgenme ürünü, koyu yeşil: $\mathrm{Na}-\mathrm{Hg}$ amalgamı ile indirgenme ürünü, pembe: aktif C/Pd- $\mathrm{N}_{2} \mathrm{H}_{4}$ ile indirgenme ürünü, açık yeşil: $\mathrm{Zn} / \mathrm{HCl}$ ile indirgenme ürünü

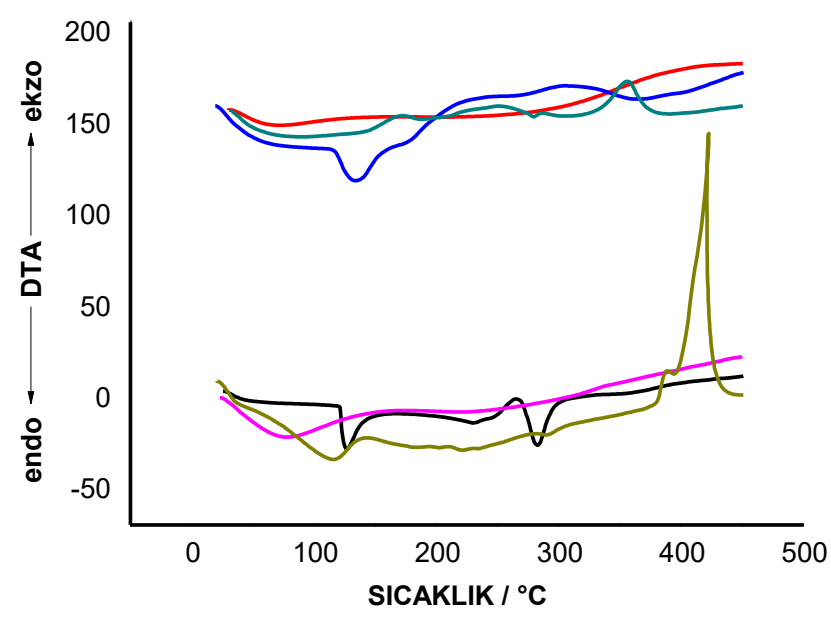

Şekil 10. Pikrik asidin kullanılan indirgenler ile indirgenmesinden elde edilen ürünlerin DTA eğrileri, siyah: pikrik asit, kırmızı: $\mathrm{Fe} / \mathrm{HCl}$ ile indirgenme ürünü, mavi: $\mathrm{Na}_{2} \mathrm{~S}_{2} \mathrm{O}_{4}$ ile indirgenme ürünü, koyu yeşil: $\mathrm{Na}-\mathrm{Hg}$ amalgamı ile indirgenme ürünü, pembe: aktif $\mathrm{C} / \mathrm{Pd}-\mathrm{N}_{2} \mathrm{H}_{4}$ ile indirgenme ürünü, açık yeşil: $\mathrm{Zn} / \mathrm{HCl}$ ile indirgenme ürünü

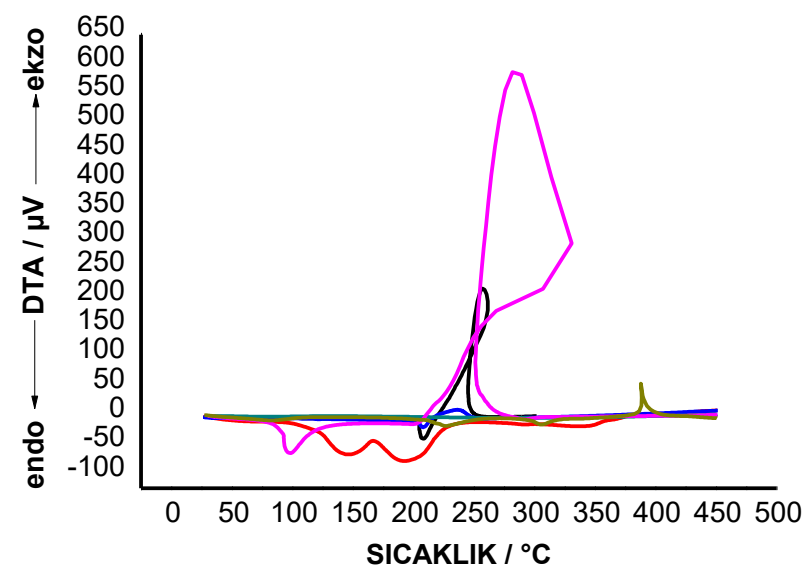

a 


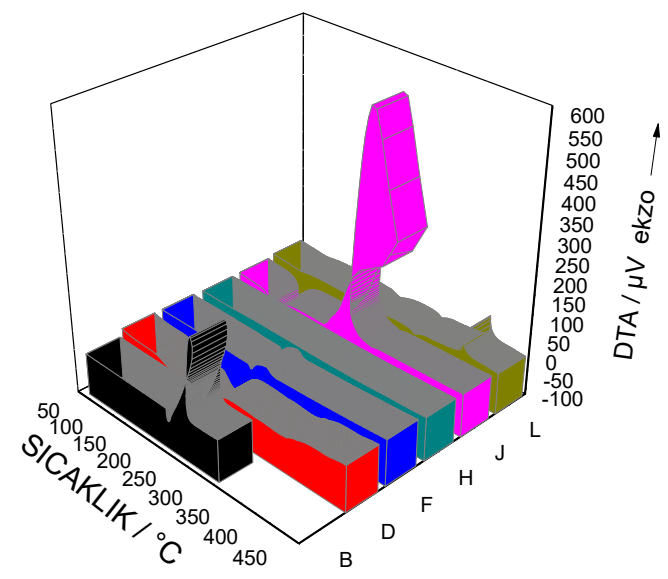

b

Şekil 11. RDX 'in kullanılan indirgenler ile indirgenmesinden elde edilen ürünlerin DTA eğrileri, siyah: RDX, kırmızı: $\mathrm{Fe} / \mathrm{HCl}$ ile indirgenme ürünü, mavi: $\mathrm{Na}_{2} \mathrm{~S}_{2} \mathrm{O}_{4}$ ile indirgenme ürünü, koyu yeşil: $\mathrm{Na}-\mathrm{Hg}$ amalgamı ile indirgenme ürünü, pembe: aktif $\mathrm{C} / \mathrm{Pd}-\mathrm{N}_{2} \mathrm{H}_{4}$ ile indirgenme ürünü, açı yeşil: $\mathrm{Zn} / \mathrm{HCl}$ ile indirgenme ürünü. İndirgenme ürünlerinin DTA eğrileri büyük ölçüde çakıştı̆̆ından, a iki boyutlu, b üç boyutlu olarak verilmiştir

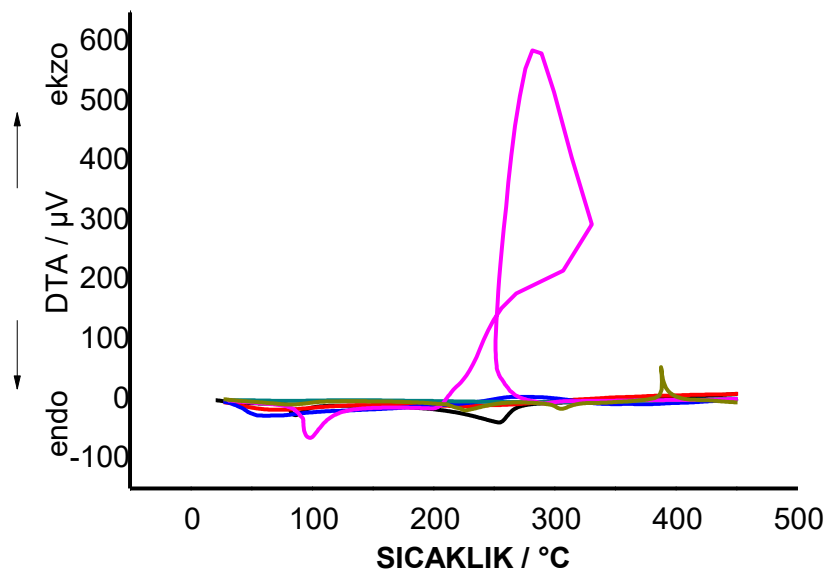

a

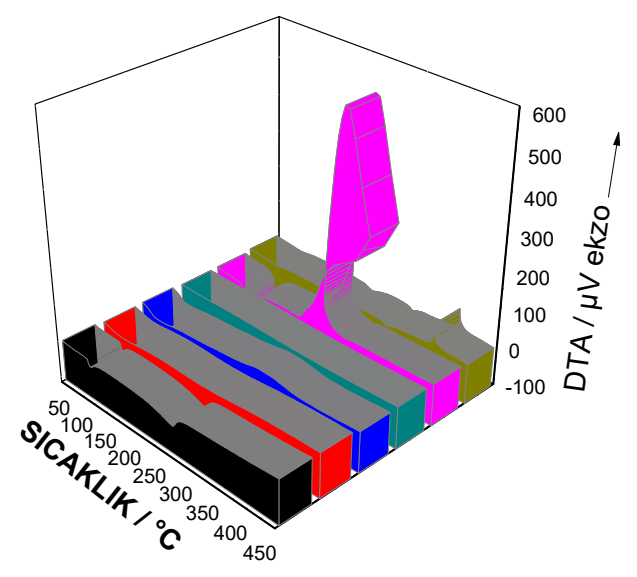

b

Şekil 12. TNT'nin kullanılan indirgenler ile indirgenmesinden elde edilen ürünlerin DTA eğrileri, siyah: TNT, kırmızı: $\mathrm{Fe} / \mathrm{HCl}$ ile indirgenme ürünü, mavi: $\mathrm{Na}_{2} \mathrm{~S}_{2} \mathrm{O}_{4}$ ile indirgenme ürünü, koyu yeşil: $\mathrm{Na}-\mathrm{Hg}$ amalgamı ile indirgenme ürünü, pembe: aktif $\mathrm{C} / \mathrm{Pd}-\mathrm{N}_{2} \mathrm{H}_{4}$ ile indirgenme ürünü, açık yeşi1: $\mathrm{Zn} / \mathrm{HCl}$ ile indirgenme ürünü. İndirgenme ürünlerinin DTA eğrileri büyük ölçüde çakıştığından, a iki boyutlu, b üç boyutlu olarak verilmiştir. 
Tablo 4 Hazırlanan enerjik maddelerin termoanalitik data ve kütle spektrometresinde en sık gözlenen $\mathrm{m} / \mathrm{z}$ değerleri

\begin{tabular}{|c|c|c|c|}
\hline $\begin{array}{l}\text { Ene } \\
\text { İndi } \\
\text { ürün }\end{array}$ & $\begin{array}{l}\text { rjik Madde ve } \\
\text { rgenme } \\
\text { lleri }\end{array}$ & $\begin{array}{l}\text { Sicaklık aralığ } /{ }^{\circ} \mathrm{C} \\
\text { Deneysel bulunan kütle kaybı / \% }\end{array}$ & $\begin{array}{l}\text { Kütle spektrumlarında en s1k } \\
\text { gözlenen } \mathrm{m} / \mathrm{z} \text { değerleri }\end{array}$ \\
\hline \multirow{6}{*}{ 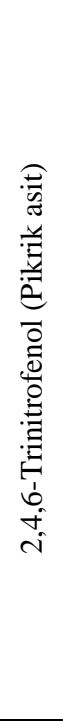 } & Pikrik asit & $\begin{array}{l}204-290 \\
99 \text { endotermik }\end{array}$ & $229,199,91,69,62,30$ \\
\hline & $\begin{array}{l}\mathrm{Fe} / \mathrm{HCl} \\
\text { indirgenme } \\
\text { ürünü }\end{array}$ & $\begin{array}{l}95-330 \\
10,702\end{array}$ & $149,85,57,43$ \\
\hline & $\begin{array}{l}\mathrm{Na} 2 \mathrm{~S} 2 \mathrm{O} 4 \\
\text { indirgenme } \\
\text { ürünü }\end{array}$ & $\begin{array}{l}190-370 \\
19.480 \text { ekzotermik }\end{array}$ & $125,85,57,43$ \\
\hline & \multirow{3}{*}{$\begin{array}{l}\mathrm{Na}-\mathrm{Hg} \\
\text { amalgam } \\
\text { İndirgeme } \\
\text { ürünü } \\
\text { Aktif C/Pd- } \\
\text { N2H4 } \\
\text { İndirgeme } \\
\text { ürünü } \\
\mathrm{Zn} / \mathrm{HCl} \\
\text { indirgeme } \\
\text { ürünü } \\
\end{array}$} & $\begin{array}{l}160-330 \\
18,542\end{array}$ & $149,85,57,43$ \\
\hline & & $\begin{array}{l}157-290 \\
29.902 \text { ekzotermik }\end{array}$ & $149,97,85,71,57,43$ \\
\hline & & $\begin{array}{l}140-260 \\
8.125\end{array}$ & $149,125,97,125,71,57,43$ \\
\hline \multirow{6}{*}{ 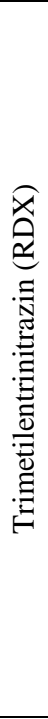 } & RDX & $\begin{array}{l}206-255 \\
99.0 \text { ekzotermik }\end{array}$ & $\begin{array}{l}147,128,120,75,55,46,43, \\
30\end{array}$ \\
\hline & $\begin{array}{l}\mathrm{Fe} / \mathrm{HCl} \\
\text { indirgenme } \\
\text { ürünü }\end{array}$ & $\begin{array}{l}104-250 \\
20.142 \text { endotermik }\end{array}$ & $128,85,57,46$ \\
\hline & \multirow{2}{*}{$\begin{array}{l}\mathrm{Na} 2 \mathrm{~S} 2 \mathrm{O} 4 \\
\text { indirgenme } \\
\text { ürünü } \\
\mathrm{Na-Hg} \\
\text { amalgam } \\
\text { İndirgeme } \\
\text { ürünü }\end{array}$} & $\begin{array}{l}190-270 \\
24,750 \text { ekzotermik }\end{array}$ & 128,64 \\
\hline & & $\begin{array}{l}100-350 \\
5,31\end{array}$ & $149,85,57,43$ \\
\hline & \multirow{2}{*}{$\begin{array}{l}\text { Aktif C/Pd- } \\
\mathrm{N} 2 \mathrm{H} 4 \\
\text { İndirgeme } \\
\text { ürünü } \\
\mathrm{Zn} / \mathrm{HCl} \\
\text { indirgeme } \\
\text { ürünü }\end{array}$} & $\begin{array}{l}210-350 \\
33.275 \text { ekzotermik }\end{array}$ & \multirow[t]{2}{*}{$125,85,57,43$} \\
\hline & & $\begin{array}{l}95-300 \\
1,77\end{array}$ & \\
\hline \multirow{6}{*}{ 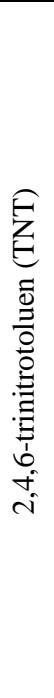 } & TNT & $\begin{array}{l}180-380 \\
99,0 \text { endotermik }\end{array}$ & $\begin{array}{l}210,193,180,163,120,89, \\
77,46,30 .\end{array}$ \\
\hline & \multirow{3}{*}{$\begin{array}{l}\mathrm{Fe} / \mathrm{HCl} \\
\text { indirgenme } \\
\text { ürünü } \\
\mathrm{Na} 2 \mathrm{~S} 2 \mathrm{O} 4 \\
\text { indirgenme } \\
\text { ürünü } \\
\mathrm{Na-Hg} \\
\text { amalgam } \\
\text { İndirgeme } \\
\text { ürünü }\end{array}$} & $\begin{array}{l}190-290 \\
10,793\end{array}$ & $149,85,57,43$ \\
\hline & & 12,001 ekzotermik & $149,85,57,43$ \\
\hline & & $\begin{array}{l}110-330 \\
15,664\end{array}$ & $149,85,57,43$ \\
\hline & \multirow{2}{*}{$\begin{array}{l}\text { Aktif C/Pd- } \\
\text { N2H4 } \\
\text { İndirgeme } \\
\text { ürünü } \\
\mathrm{Zn/HCl} \\
\text { indirgeme } \\
\text { ürünü }\end{array}$} & $\begin{array}{l}160-330 \\
42,929 \text { ekzotermik }\end{array}$ & $149,85,57,43$ \\
\hline & & $\begin{array}{l}130-365 \\
15,17\end{array}$ & $125,85,57,43$ \\
\hline
\end{tabular}




\section{Sonuç ve Yorum}

Nitro benzenin metalik indirgenler ile aniline indirgenmesi uzun süreden beri bilinen ve endüstriyel olarak kullanılan bir prosestir [12]. Bu çalışmada bu düşünce paralelinde nitro gruplarının amino gruplarına indirgenmesi üzerine tasarlanmış bir çalışmadır fakat bu çalışmada fark indirgenen enerjik maddelerde birden fazla nitro grubu olmasıdır. Bunun yanısıra kullanılan indirgenler çözünebilen indirgenler değildirler, sadece $\mathrm{Na}_{2} \mathrm{~S}_{2} \mathrm{O}_{4}$ suda çözünebilmektedir, bu sebepten dolayı indirgeme tepkimeleri çözelti - indirgen ara yüzeylerinde gerçekleştiğinden tepkimelerin kinetik değerleri hakkında bir bilgi sahibi olabilmek mevcut verilerle mümkün değildir. Bununla birlikte gerek IR spektroskopi gerek TG-DTA sonuçları enerjik maddelerdeki nitro gruplarının büyük ölçüde indirgendiğini gösteriyor. Şekil 1, Şekil 2, Şekil 3, Şekil 4, Şekil 5, ve Şekil 6'da verilen spektrumlara bakılacak olursa pikrik asit, RDX ve TNT enerjik maddelerinin hepsinde $1300-1340 \mathrm{~cm}^{-1}$ arasında tipik $v \mathrm{~N}=\mathrm{O}$ esneme titreşimlerinin ortak olduğu görülmektedir. Pikrik asit, RDX ve TNT Şekil 1, Şekil 2, Şekil 3, Şekil 4, Şekil 5, ve Şekil 6'da siyah hatlarla çizilmiştir. İndirgenme ürünlerinde hemen hemen tamamında bu sinyalin kaybolduğu ve 3200-3500 $\mathrm{cm}^{-1}$ arasında geniş absorpsiyon bantlarının ortaya çıktığ görülüyor. Olası olarak bu ortaya çıkan bantlar $v \mathrm{~N}-\mathrm{H}$ esnemelerinden kaynaklanmaktadır. Bununla birlikte indirgeme sonucunda hangi ürünün veya ürün karışımının meydana geldiğine karar verebilmek mümkün değildir. Çünkü aminofeollerin ve aromatik diaminlerin halkalaşma tepkimeleri verdikleri uzun zamandan beri bilinmektedir [18-25]. Literatürde özellikle TNT'nin elektrokimyasal indirgenmesiyle 2,4,6-triaminotoluen oluştuğuna dair birçok çalışma bulunmaktadır [26-31]. Ancak bunların hepsi preparatif çalışmalar değildir, hatta bir kısmı sadece teorik hesaplamadır. Bu çalışmadada IR spektroskopi yöntemi nitro gruplarının amin gruplarına indirgendiğini kanıtlıyor ama ürünlerin hakkında bize net bir sonuç vermemektedir. Ancak bu çalışmanın amacı herhangi bir ürün elde etmek değil enerjik maddeleri başka bir deyişle patlayıcı maddeleri indirgeme tepkimeleriyle tehlikesiz güvenli maddeler haline getirebilmektir. Bu çalışmada bu amaca büyük ölçüde TG - DTA çalışmaları yanıt verebilmektedir. Patlayıcı maddeler bilindiği gibi darbe, sürtünme ve termal hassasiyetleri olan maddelerdir. Ani bir darbe ile uygulanan bir basınç veya bir kıvılcım ya da sürtünme gibi etki ile iç tepkime sonucu çok hızlı parçalanıp gaz ürünlere dönüşen maddelerdir. Bu sebepten dolayı belli 1sıtma hızlarında çok küçük bir sicaklık aralığında mevcut kütlesinin hemen hemen tamamını gaz ürünlere dönüştürürler ve bu olay çok hızlı olduğu için birdenbire ortaya çıkan gazlardan ve olayın genelde ekzotermik olmasından dolayı ortama bir şok dalgası yayarlar (blast) ki bu da patlama tepkimesi olarak tanımlanır. Bu sebepten dolayı indirgeme tepkimelerinden elde edilen ürünlerin patlama riski taşıyıp taşımadıkları en kolay TG - DTA spektrumları ile tespit edilebilir. Aşağıda Şekil 13'te RDX'in TG-DTA eğrisi verilmiştir, şekilde $205-206^{\circ} \mathrm{C}$ sıcaklıktan sonra RDX maddesinin birden kütlesinin kaybolduğu ve olayın ekzotermik olduğu görülmektedir. 


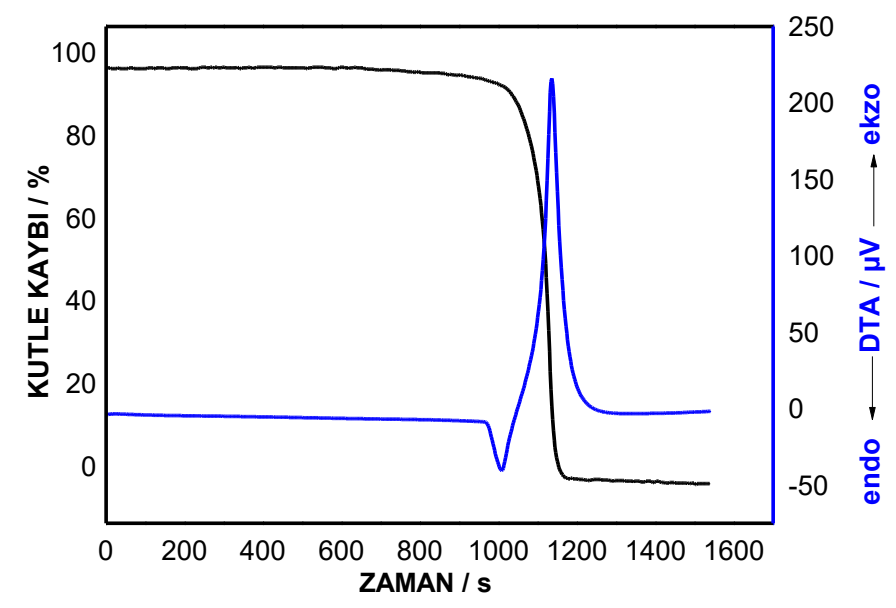

$\mathbf{a}$

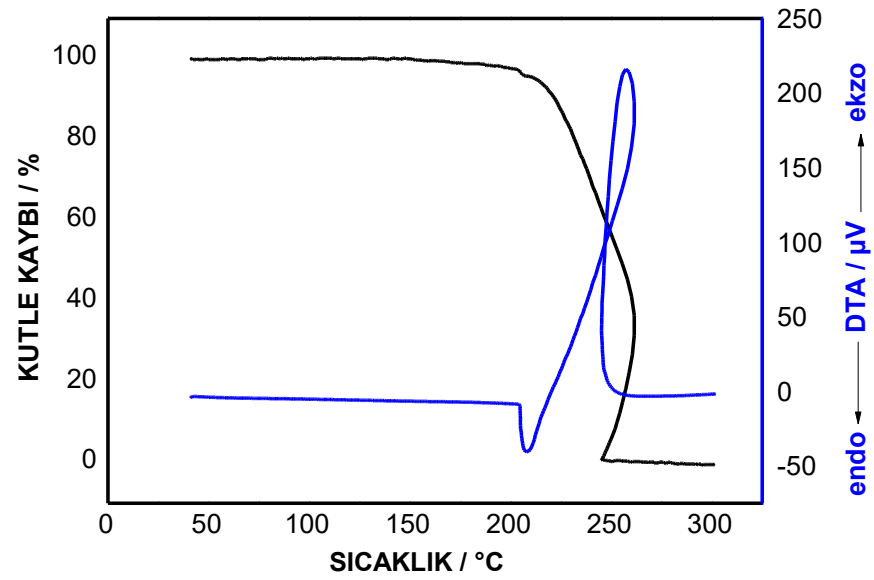

b

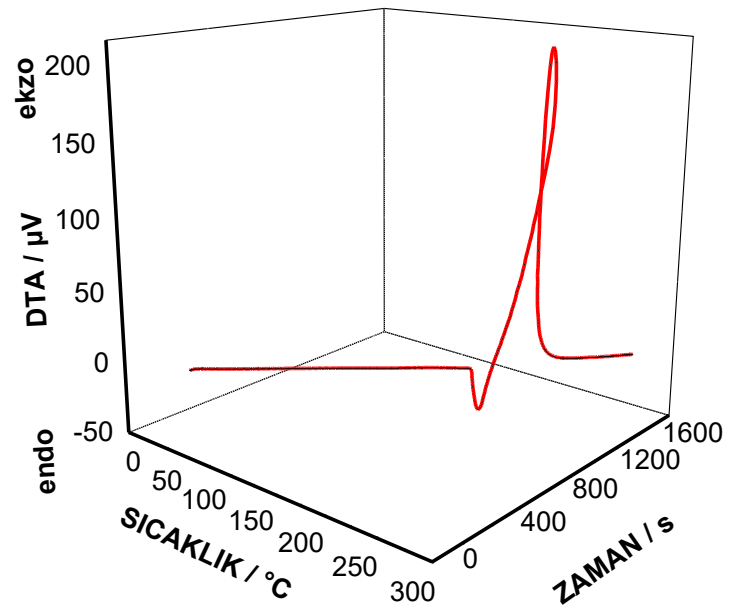

c

Şekil 13. RDX enerjik maddesinin (a) zaman-DTA, (b) sıcaklık-DTA ve (c) sıcaklık- zaman-DTA üç boyutlu DTA eğrileri. Termal parçalanma (patlama) tepkimesi sırasında DTA eğrisinin deformasyonu üç boyutlu grafikte daha net görülmektedir.

Şekil 13'de kütle kaybı ve sıcaklık iki y eksenli bir grafikte zamana karşı grafiklenmiştir ve ekzotermik sinyal Gaussian tipi bir eğri şeklinde gözlenmektedir. Oysa TG - DTA 
çalışmalarında alışılagelmiş olarak kütle kaybı ve DTA verileri sıcaklığa karşı grafiklenir. RDX maddesinin TG-DTA eğrilerini sıcaklığa karşı grafiklenecek olursa elde edilen eğrilerde bir anomali gözlenir, bu anomali Şekil 14'de görülmektedir. DTA eğrileri bir geri dönüş gösterdiği gibi kütle kaybı eğrileri belli bir süre için negatif eğime sahip olur. Bunun sebebi patlama tepkimesinin çok hızlı olmasıdır. Çok hızlı bir şekilde ortaya çıkan gaz kütlesi ekzotermik tepkimenin 1sısını absorpladığı için hızla etrafa yayılır ve absorpladıkları 1sıyı beraberinde götürdükleri için kısa bir süre patlama mahalinin sıcaklığı biraz azalır, sonra TG cihazının firın etkisiyle tekrar artmaya başlar, patlama tepkimelerinde sıkça gözlenen bu olay dikkat edilirse patlama ürünlerinde de görülmektedir. Şekil 11 ve Şekil 12'de özellikle aktif C/Pd- $\mathrm{N}_{2} \mathrm{H}_{4}$ ile indirgenmiş üründe pembe hatlarla çizilmiş olarak görülmektedir. İndirgen madde nitro gruplarının bir kısmını veya tamamını indirgemiş olmakla birlikte malzemenin patlayıcı özelliği ortadan kalkmamıştır. Şekil 7, Şekil 8, Şekil 9, Şekil 10, Şekil 11 ve Şekil 12'de verilen sonuçlar enerjik maddelerin patlama tehlikelerinin indirgenme tepkime tepkimeleri sonunda kalıc1 olup olmadığını göstermektedir. Dikkatlice incelenirse $\mathrm{Fe} / \mathrm{HCl}$ ve $\mathrm{Na}-\mathrm{Hg}$ amalgamı ile indirgenmiş olan ürünlerde hiçbir ekzotermik tepkime görülmemektedir, TG eğrilerine bakılırsa bu indirgenme tepkime ürünlerinde küçük bir sıcaklık aralığında bir kütle kaybıda görülmüyor. $\mathrm{Na}_{2} \mathrm{~S}_{2} \mathrm{O}_{4}$ ve aktif $\mathrm{C} / \mathrm{Pd}-\mathrm{N}_{2} \mathrm{H}_{4}$ ile indirgenmiş olan ürünlerde ise patlama tehlikesinin ortadan kalkmadığ 1 görülmektedir. $\mathrm{Zn} / \mathrm{HCl}$ ile yapılan indirgemelerde ise $400^{\circ} \mathrm{C}$ civarında ekzotermik kütle kayıpları görülmektedir. Şekil 1, Şekil 2, Şekil 3, Şekil 4, Şekil 5 ve Şekil 6'da verilen IR spektrumları incelendiğinde sadece $\mathrm{Fe} / \mathrm{HCl}$ ve $\mathrm{Na}-\mathrm{Hg}$ amalgamı ile indirgemelerde elde edilen ürünlerde 1300-1340 $\mathrm{cm}^{-1}$ de gözlenen tipik $v \mathrm{~N}=\mathrm{O}$ esnemelerinin tamamen kaybolduğu görülmekte, diğer indirgenlerle yapılan indirgeme ürünlerinde bu bölge ya belirsiz ya da bu bölgedeki tipik nitro sinyalinin tamamen kaybolmadığı ancak zayıfladığı görülmektedir. Bu noktada $\mathrm{Fe} / \mathrm{HCl}$ ve $\mathrm{Na}-\mathrm{Hg}$ amalgamı ile yapılan indirgemelerde tepkime kinetiğinin daha hızlı olduğu düşünülebilir ve indirgemenin tamamen çalışma süresi sonunda tamamlandığ diğer indirgenlerle olan tepkimelerin daha yavaş olduğu için tüm enerjik maddenin indirgenmediği yorum olarak verilebilir ancak bu çalışmanın amacı enerjik maddelerin kimyasal olarak bertarafı olduğundan bu çalışma için en uygun indirgen malzemelerin $\mathrm{Fe} / \mathrm{HCl}$ ve $\mathrm{Na}-\mathrm{Hg}$ amalgamı olduğu öngörülmektedir.

Şekil 10, Şekil 11 ve Şekil 12'de enerjik maddeler siyah hatlarla gösterilmiştir. Dikkat edilirse pikrik asidin ve TNT'nin ekzotermik bir tepkimeyle patlamadığı görülmektedir. $\mathrm{Bu}$ maddenin özelliğinden kaynaklanmaktadır. Pikrik asit $122,78^{\circ} \mathrm{C}$ sicaklıkta erimekte ve bu sıcaklıktan sonra gaz halinde ortamdan uzaklaşmaktadır, sıcaklık pikrik asidin patlama sicaklığ 1 olan $280{ }^{\circ} \mathrm{C}$ 'a ulaşmadan pikrik asidin tamamı ortamdan uzaklaştığ1 için patlama gözlenmez tam tersi pikrik asit gaz haline geçtiği için endotermik bir patlama gözlenir, aynı durum $81,40^{\circ} \mathrm{C}$ sıcaklıkta eriyen TNT içinde söz konusudur. Oysa kapalı bir pan içinde deney gerçekleştirilseydi patlama net olarak gözlenecektir. İndirgeme ürünlerinin çoğunda belli bir sıcaklıkta patlama tepkimesini andıran kütle kayıpları veya ekzotermik tepkimeler görülmemektedir. Sadece RDX ve TNT'nin aktif C/Pd- $\mathrm{N}_{2} \mathrm{H}_{4}$ ile elde edilen indirgenme ürünlerinde net bir ekzotermik tepkime gözlenmektedir. Tablo 4'de indirgenme ürünlerinde gözlenen ekzotermik tepkimeler belirtilmiştir.

İndirgenme ürünlerinin saf bir madde olup olmadığı yoksa bir karışım olup olmadığı bu çalışmadaki mevcut verilerle tam olarak anlaşılacak durumda değildir. IR spektrumları indirgenme ürünlerinde $-\mathrm{NH}$ veya $-\mathrm{NH}-\mathrm{OH}$ bantları oluşmasının yüksek olasılıkta olduğunu göstermektedir. Bunun yanında ürünlerin kütle spektrumlarında gözlenen fragmentler enerjik maddenin başka bir maddeye dönüştüğünü göstermektedir. Deneysel kısımda saf enerjik maddelerin $70 \mathrm{eV}$ elektronlarla iyonlaştırma ile verilen $\mathrm{m} / \mathrm{z}$ sinyalleri 
ile ürünlerin bu değerleri arasında önemli farklar vardır. Pikrik asit ve RDX maddelerinde moleküler sinyal aynı zamanda temel sinyaldir, buna karşın saf TNT'nin kütle spektrumunda moleküler sinyal hiç gözlenmemektedir, gözlenen en yüksek fragment sinyali $\mathrm{m} / \mathrm{z}=210$ değerinde görülmektedir, bu durum 1958 'den beri bilinen bir durumdur [18]. Orto pozisyonda nitro grubu bulunduran malzemeler termal bozunmalarında halkalaşma ürünleri vermektedirler. Şekil 14 ve Tablo 4'de verilen ürünlerin $\mathrm{m} / \mathrm{z}$ değerleri incelenecek olursa tüm indirgenme ürünlerinde kullanılan enerjik maddelerin moleküler kütlelerine yakın bir değerin olmadığı, tüm $\mathrm{m} / \mathrm{z}$ değerlerinin indirgenme sonucunda ortaya çıkan maddelerin fragmentleri olduğu anlaşılmaktadır. IR spektrumlarından görüldüğ̈̈ gibi nitro grupları amin veya hidroksilamin gruplarına indirgenmiş olduğu sonucuna varılır, Şekil 15 'de paylaşılan ürünlerdeki sık gözlenen $\mathrm{m} / \mathrm{z}$ değerleri de indirgenme ürünleri ile daha fazlasıyla uyuşum halindedir. Bununla birlikte tüm $\mathrm{m} / \mathrm{z}$ değerlerini açıklayabilmek mümkün olmamıştır.

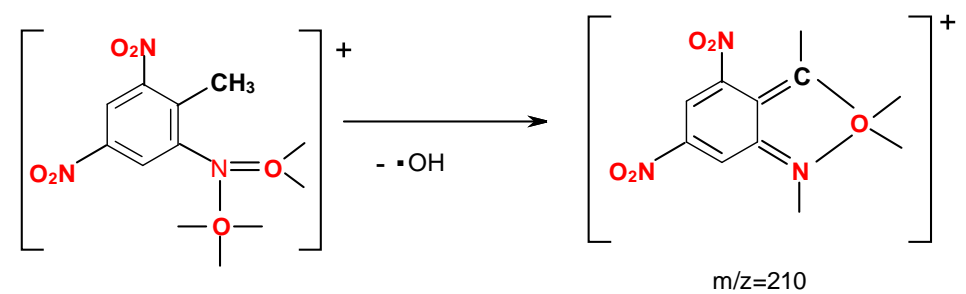

Şekil 14. TNT enerjik maddesinin kütle spektrumunda gözlenen ana fragmentin oluşum tepkimesi<smiles>COC1(C)C=C2C(N)=CC(N)=CC2N1C</smiles>

a<smiles>CC#CN</smiles>

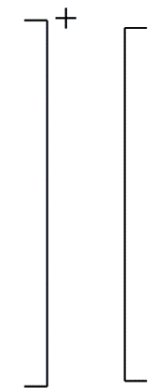<smiles>ONc1cc(N=[As])ccc1O</smiles>

b<smiles>C=CN</smiles>

d

Şekil 15. Enerjik maddelerin indirgenme ürünlerinin kütle spektrumlarında en sık gözlenen m/z değerlerine ait olası fragmentler

\section{Araştırmacıların Katkı Oranı Beyanı}

Abdullah YÜCEL: Araştırma, Orijinal Taslak Yazımı, İnceleme ve Düzenleme

Orhan ATAKOL: Kaynak/Materyal/Malzeme Temini, Doğrulama, Denetim/Gözlem/Tavsiye.

\section{Destek ve Teşekkür Beyanı}

Bu çalışmanın yazarları olarak herhangi bir destek ve teşekkür beyanımız bulunmadığını bildiririz.

\section{Çatışma Beyanı}

Bu çalışmanın yazarları olarak herhangi bir çatışma beyanımız bulunmadı̆̆ını bildiririz. 


\section{Etik Kurul Onayı ve/veya Aydınlatılmış Onam Bilgileri}

Bu çalışmanın yazarları olarak herhangi bir etik kurul onayı ve/veya aydınlatılmış onam bilgileri beyanımız bulunmadığını bildiririz.

\section{Kaynakça}

[1] T. M. Klapötke," Chemistry of High Energy Materials," Munich: Walter de Gruyter, 2017, pp. 11.

[2] P. Politzer and J. S. Murray, "Energetic Materials, Part 2, Detonation, Combustion," New Orleans: Elsevier, 2003, pp. 25-46.

[3] R. W. Shaw, T. B. Brill and D. L. Thomson, "Overviews of Recent Research on Energetic Materials," Singapore: Word Scientific Publishers Co Pte. Ltd., 2005, pp. 473.

[4] J. Akhavan, "The Chemistry of Explosives," London: RSC Paperbacks, 1998, pp. 7-14.

[5] J. P. Agrawal, "High Energetic Materials," Weinheim: Wiley VCH Verlag GmbH, 2010, pp. 1-32.

[6] N. Kubota, "Propellants and Explosives," Weinheim: Wiley VCH Verlag GmbH, 2007, pp. 23-39.

[7] Bozkuş Sinecan İrem, Şen Nilgün (2019). 2,4,6-Trinitrofenol ve Trinitrotoluen ile 1-Bromopiren Arasında Oluşan Yeni Enerjik Ko-kristalin Karakterizasyonu ve Enerjik Performans Özellikleri. Süleyman Demirel Üniversitesi Fen Edebiyat Fakültesi Fen Dergisi, 14, 136-149.

[8] Bozkuş Sinecan İrem, Hope Karl S, Yüksel Bayram, Atçeken Nurunnisa, Nazir Hasan, Atakol Orhan, Şen Nilgün (2019). Characterization and properties of a novel energetic Co-crystal formed between 2,4,6-Trinitrophenol and 9-Bromoanthracene. J. Mol. Struct., 1192, 145-153.

[9] M. Qasim, Y. Kholod, L. Gorb, D. Magers, P. Honea and J. Leszczynski, “Application of quantumchemical approximations to environmental problem", Chemosphere, 69, 1144-1150, 2007.

[10] T. Brink, "Introduction to Green Energetic Materials," West Sussex: John Wiley \&Sons, 2014, pp. 211.

[11] E. Breitmaier and G. Jung, "Organische Chemie," 6. Überarbeitete Auflage: Thimie Georg Verlag, Tubingen, 2009, pp. 476.

[12] N. Ono, "The Nitro Group in Organic Synthesis," New York: Wiley\&VCH, 2001, pp. 370-378.

[13] G. Bunte, H. H. Krause, T. Hirth, "Disposal of energetic materials by alkaline pressure hydrolysis and combined techniques," Propellants, Explosives, Pyrotechnics 22, 259-269, 1997.

[14] H. M. Heilmann, U. Wiesmann, M. K. Stenstrom, "Kinetics of the alkaline hydrolysis of high explosives RDX and HMX in aqueous solution and adsorbed to activated carbon," Environ. Sci. Technol. 30, 1485-1492, 1996.

[15] B. S. Furniss, A. J. Hannaford, P. W. G. Smith and A. R. Tatschell, "Vogel's Textbook of Practical Organic Chemistry," London: Longman Scientific\&Technical, fifth edition, 1989, pp. 976.

[16] J. B. Ledgard, “The Preparatory Manual of Explosives," 3th Edition, Seattle: Independently Published, 2007, pp. 116-117.

[17] J. B. Ledgard, “The Preparatory Manual of Explosives, ”3th Edition, Seattle Independently Published, 2007, pp. 180.

[18] B. S. Furniss, A. J. Hannaford, P. W. G. Smith, and A. R. Tatschell, "Vogel's Textbook of Practical Organic Chemistry," London: Longmann Scientific\&Technical, fifth edition, 1989, pp. 464.

[19] E. Breitmaier, G. Jung, “Organische Chemie, ” 6. Überarbeitet Auflage, Tubingen: Thimie, 2009, pp. 375-377.

[20] N. Ono, “The Nitro Group in Organic Synthesis” New York: Wiley\&VCH, 2001, pp.170-180.

[21] J. E. House, “Inorganic Chemistry” Academic Press, Elsevier, 2008, pp. 540-541.

[22] K. H. Büchel, H. H. Moretto, P. Woditsch, “Industrial Inorganic Chemistry”, 2nd Edition, New York: Wiley\&VCH, 2000, pp. 121-122.

[23] A. S. Bailey, J. R. Case, “4, 6-dinitrobenzofuroxan, nitrobenzodifuroxan and benzotrifuroxan: a new series of complex-forming reagents for aromatic hydrocarbons," Tetrahedron, 3, 113-131, 1958.

[24] G. O. Reddy, B. K. M. Murali and A. K. Chotterjee, "Thermal study on picryl azide (2-azido-1,3,5trinitrobenzene) decomposition using simultaneous thermogravimetry and differential scanning calorimetry," Propellants, Explosives, Pyrotechnics, 8, 29-33, 1983.

[25] A. B. Shremetev, N. S. Aleksandrova, N. V. Ignat'ev and M. Schulte, "Straightforward one-pot synthesis of benzofuroxans from o-halonitrobenzenes in ionic liquids," Mendeleev Commun., 22, 2, 95-97, 2012.

[26] E. Özkaramete, N. K. Şenocak, E. K. İnal, S. Öz, I. Svoboda and O. Atakol, "Experimental and computational studies on the thermal degradation of nitroazidobenzenes," Propellants, Explosives, Pyrotechnics, 38, 113-119, 2013.

[27] D. Sarkar, A. Som, T. Pradeep, "Catalytic paper spray ionization mass spectrometry with metal nanotubes and the detection of 2,4,6-trinitrotoluene," Anal. Chem., 89, 11378-11382, 2017.

[28] A. Gupta and M. A. Widdowson, "Modeling of complex reductive biodegradation kinetics of recalcitrant organic contaminants," J. Environ. Eng., 143, 04017033/1-04017033/9, 2017. 
[29] X. Ni, Y. Zhao and Q. Song, "Electrochemical reduction and in-situ electrochemiluminescence detection of nitroaromatic compounds," Electrochim., Acta, 164, 31-37, 2015.

[30] C. K. Chua, M. Pumera and L. Rulisek, "Reduction Pathways of 2,4,6-Trinitrotoluene: An Electrochemical and Theoretical Study," J. Physical Chem. 116, 4243-4251, 2012.

[31] V.A.Kashaev, G. Khisamutdinov, S.A. Shevelev, S. I. Valeshnii, A. Shakhnes and A.P. Bavrina, "Preparation of 2,4,6-triaminotoluene and its salts with inorganic acids from 2,4,6-trinitrotoluene," Theor. Found. Chem. Eng., 42, 650-656, 2008.

[32] G. Anu, S. Dhanashree and M. Sukhendu, "Catalytic Reduction of Toxic Nitroarenes in Aqueous Medium Using Worm-Like Rhodium Nanoparticles”, Chem. Select., 2, 9718-9721, 2017. 